\title{
Study of electrospun cellulose acetate fibers
}

DOI: $10.35530 / 1 T .069 .05 .1511$

\section{REZUMAT - ABSTRACT}

\section{Studiu asupra fibrelor de acetat de celuloză electrofilate}

Obiectivul acestui studiu a fost prepararea nanofibrelor de acetat de celuloză prin electrofilare, utilizând un amestec de solvenți. Soluțiile de acetat de celuloză au fost electrofilate din sisteme de solvenți binare și ternare, cum ar fi N,N-dimetilformamidă, acetonă și cloroform. S-au investigat efectele sistemelor de solvenți asupra caracteristicilor structurale, morfologice și mecanice ale fibrelor.

Cuvinte-cheie: electrofilare, acetat de celuloză, nanofibre electrofilate

\section{Study of electrospun cellulose acetate fibers}

The objective of this work was the preparation of cellulose acetate nanofibers by electrospinning using a mixture of solvents. Cellulose acetate solutions were electrospun from binary and ternary solvent systems, such as $\mathrm{N}, \mathrm{N}$-dimethylformamide, acetone and chloroform. The effects of the solvent systems on the structural, morphological and mechanical characteristics of the fibers were investigated.

Keywords: electrospinning, cellulose acetate, electrospun nanofibers

\section{INTRODUCTION}

In the recent years, nanoscience and nanotechnology have developed rapidly, leading to major advances in nanomaterials processing and characterization. From this category, one-dimensional materials nanofibers - present extremely high specific surface area due to small diameters and nanofiber membranes showing high ratio of surface area to volume, high porosity, characterized by high pore interconnectivity [1]. The unique characteristics of nanofibers make them an important candidate for a large number of industrial applications [2-4].

A significant number of methods can be used to obtain nanofibers: interfacial polymerization [5], melt spinning [6], solution spinning [7] and electrospinning $[8,9]$. Electrospinning is a simple and versatile process that uses the electrical field to obtain the polymeric nanofibers from solution. This method for preparing nanofibers allows the use of a large number of polymers [10-11]. Some of these polymers are polyvinyl pyrrolidone (PVP), polylactic acid (PLA), chitosan, polyester urethane (PEU), polyvinyl alcohol (PVA), polystyrene, polyacrylonitrile (PAN) and chitin [12-16].

From a wide range of polymeric materials, cellulose acetate (CA) belongs to the new generation of environmentally friendly products that fit into the new research directions due to the requirements of developing materials with minimal impact on the environment, using renewable resources as much as possible. Numerous single and binary solvent systems have been used for obtaining electrospun CA fibers.
By using traditional single solvent systems for preparing CA solution, such as N,N-dimethylformamide (DMF) [17], chloroform [18], acetic acid [19], N,N-dimethylacetamide (DMAc) [20] and acetone [21], some problems appear regarding to the obtaining of continuous and bead-free electrospun fibers. The physical properties of the solvent system can be improved by using a binary solvent system of two solvents with different dielectric constant and boiling point of both solvents. Such binary solvent systems for CA solution are acetone/ethanol [22], acetic acid/water [23] or DMAc/acetone [21].

In this paper, a new ternary solvent system consisting in DMF/Acetone/Chloroform was developed in order to obtain continuous CA fibers by electrospinning method. The influence of the solvents on the morphology and mechanical properties of CA fibers has been studied.

\section{EXPERIMENTAL WORK}

\section{Materials}

In this study, cellulose acetate (CA) with a molecular mass of 30,000 purchased from Aldrich was used as polymer source. The solvents used for dissolving $C A$ were acetone (A) with $1.3 \mathrm{~g} / \mathrm{cm}^{3}$ density, purchased from Aldrich, N,N-dimethylformamide (D) with 0.94 $\mathrm{g} / \mathrm{cm}^{3}$ density, purchased from Alfa Aesar, and chloroform (C) with $1.485 \mathrm{~g} / \mathrm{cm}^{3}$ density, purchased from Chimreactiv. All materials were used without any purification. 


\section{Preparation of electrospinning solutions}

Five CA solutions with concentrations of $12 \%$ wt. were prepared in the binary system of solvents DMF/ Acetone (table 1). Also, four CA solutions with concentrations of $12 \%$ wt. were prepared in the ternary system of solvents DMF/Acetone/Chloroform (table 2). A good dissolution of the CA in binary or ternary solvent system is very important in achieving good morphological properties of the electrospun fibers. Thus, CA was dissolved in the solvents system by magnetic stirring at room temperature for 2 hours, at a rotational speed of $480 \mathrm{rpm}$ and the obtained solutions were used immediately in the electrospinning process.

Table 1

\begin{tabular}{|c|c|c|}
\hline Solution & CA (\% wt.) & D/A (v/v) \\
\hline ACAD100 & 12 & $1 / 0$ \\
\hline ACAD75 & 12 & $3 / 1$ \\
\hline ACAD50 & 12 & $1 / 1$ \\
\hline ACAD25 & 12 & $1 / 3$ \\
\hline ACAD0 & 12 & $0 / 1$ \\
\hline
\end{tabular}

Table 2

\begin{tabular}{|c|c|c|}
\hline Solution & CA (\% wt.) & D/A/C (v/v/v) \\
\hline DAC111 & 12 & $1 / 1 / 1$ \\
\hline DAC112 & 12 & $1 / 1 / 2$ \\
\hline DAC121 & 12 & $1 / 2 / 1$ \\
\hline DAC211 & 12 & $2 / 1 / 1$ \\
\hline
\end{tabular}

an ATR JASCO PRO 470-H module. All the samples were measured directly on the diamond crystal surface, in the range of $400-4000 \mathrm{~cm}^{-1}$, at a resolution of $4 \mathrm{~cm}^{-1}$ and 50 scans for each spectrum.

Wettability testing of the obtained CA fibers mats was made using the sessile drop method. Contact angle of the polymeric nonwoven mats was determined with distilled water by using an optical microscope equipped with a camera for images acquisition on the computer and the images were processed using the software Image J, Drop Analysis - Drop Snake.

Mechanical properties (tensile strength) of the CA electrospun nonwoven fibers mats were measured by using a mechanical testing machine, model LFM 30 kN, Walter \& Sai AG Switzerland.

\section{RESULTS AND DISCUSIONS}

The physical properties of the solvents (table 3) [24], especially the volatility, have a major influence on the formation and the morphology of fibers obtained by electrospinning method. By using volatile solvents such as acetone, the tip of the needle can be easily blocked with the polymer because the solvent evaporates quickly. In these researches, the partial elimination of this problem was obtained by using a binary solvent system for dissolving $\mathrm{CA}$ with close volatility, such as acetone (boiling point $56^{\circ} \mathrm{C}$ ) and chloroform (boiling point $61^{\circ} \mathrm{C}$ ). This small difference of solvents volatility did not lead to the obtaining of uniform and beads-free CA fibers (the study is not presented here).

Partial solving of this problem was accomplished by using a binary solvent system. This binary mixture contains two solvents in different ratios that show a

Table 3

\begin{tabular}{|c|c|c|c|c|c|c|}
\hline Solvent & $\begin{array}{c}\text { Molecular } \\
\text { weight } \\
{[\mathbf{g} / \mathbf{m o l}]}\end{array}$ & $\begin{array}{c}\text { Boiling } \\
\text { point } \\
{\left[{ }^{\circ} \mathbf{C}\right]}\end{array}$ & $\begin{array}{c}\text { Electrical } \\
\text { conductivity at } \mathbf{2 5}^{\circ} \mathbf{C} \\
{\left[\mathbf{S} \cdot \mathbf{m}^{-1} \mathbf{]}\right.}\end{array}$ & $\begin{array}{c}\text { Latent } \\
\text { heat } \\
{\left[\mathbf{k J} \cdot \mathbf{m o l}^{-1}\right]}\end{array}$ & $\begin{array}{c}\text { Surf. tension } \\
\text { at } \mathbf{2 0} \mathbf{}^{\circ} \mathbf{C} \\
{\left[\mathbf{m N} \cdot \mathbf{m}^{-1}\right]}\end{array}$ & $\begin{array}{c}\text { Abs. viscosity } \\
\text { at } \mathbf{2 5}^{\circ} \mathbf{C} \\
{[\mathbf{m P a} \cdot \mathbf{s}]}\end{array}$ \\
\hline Acetone & 58 & 56 & $5.0 \cdot 10^{-7}$ & 29.6 & 23.30 & 0.33 \\
\hline Chloroform & 119 & 61 & $<1.0 \cdot 10^{-8}$ & 29.4 & 27.16 & 0.57 \\
\hline DMF & 73 & 153 & $6.0 \cdot 10^{-6}$ & 42.1 & 35.00 & 0.82 \\
\hline
\end{tabular}

In order to obtain the nonwoven CA fibers mats on an aluminium foil substrate by electrospinning method, a NaBond unit was used with an applied voltage of $18 \mathrm{kV}$, a solution flow rate of $1.8 \mathrm{~mL} / \mathrm{h}$, nozzle size spinneret of $0.8 \mathrm{~mm}$, spinneret-to-collector distance of $20 \mathrm{~cm}$ and a stationary substrate.

\section{Characterization}

Morphological characterization of the CA obtained fibers was performed with scanning electron microscopy (SEM) using a FESEM/FIB/EDS Workstation Auriga produced by Carl Zeiss Germany, with an acceleration voltage of $5 \mathrm{kV}$, using the SESI detector.

The chemical structure of CA and CA fibers was determined by FTIR measurements performed by using a Jasco FTIR-4200 spectrophotometer, connected to higher difference of volatility. Therefore, the binary DMF/Acetone system in various ratios can be used to dissolve CA and to obtain fibers through electrospinning. In this research, we went further in order to obtain continuous and uniform CA fibers and we used a ternary solvent system such as DMF/Acetone/ Chloroform.

\section{FTIR characterization}

The FTIR spectrometry (figure 1) was used to study the influence of the solvent type on the chemical structure of cellulose acetate (CA). The recorded spectra look similar and present the characteristic bands of cellulose acetate [25-27]: the bands from the $2800-3000 \mathrm{~cm}^{-1}$ region assigned to the stretching vibrations of $\mathrm{C}-\mathrm{H}\left(\mathrm{CH}_{2}\right.$ groups [28], $1735 \mathrm{~cm}^{-1}$ 


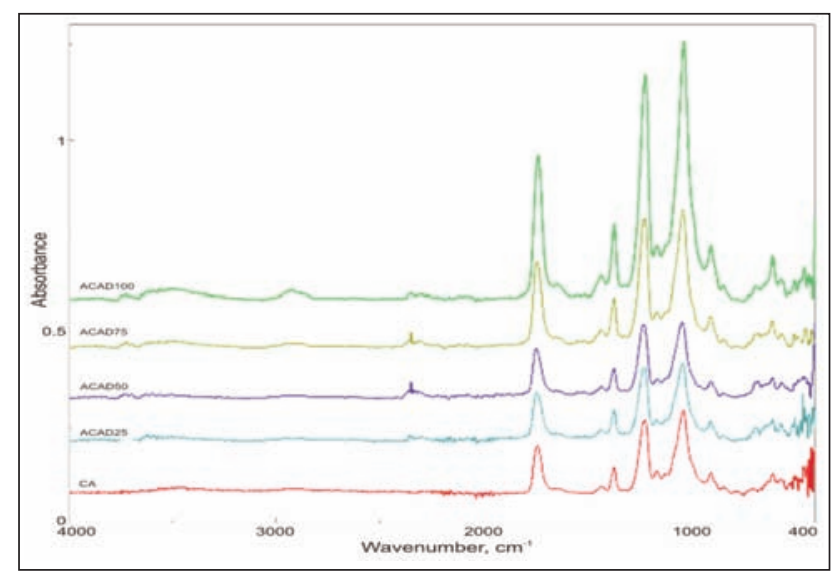

a

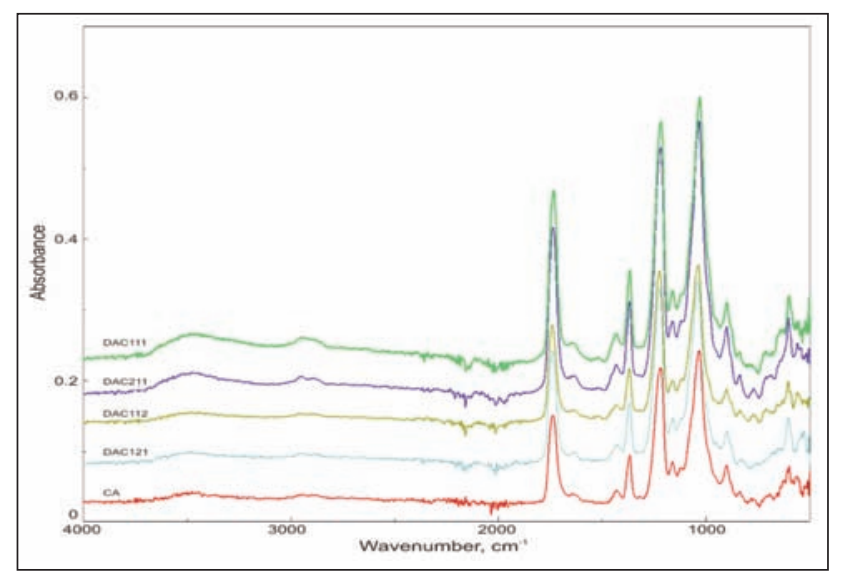

b

Fig. 1. FTIR spectra of CA crystals and of the obtained CA fibers from D/A binary solvent system (a) and D/A/C ternary solvent system (b)

( $\mathrm{C}=\mathrm{O}$ stretching of acetyl or carboxylic acid), 1435 $\mathrm{cm}^{-1}\left(\mathrm{CH}_{2}\right.$ or $\mathrm{OH}$ in plane bending), $1370 \mathrm{~cm}^{-1}(\mathrm{CH}$ deformation from $\left.\mathrm{CH}_{3}\right), 1220 \mathrm{~cm}^{-1}(\mathrm{C}-\mathrm{O}$ stretching of acetyl group), $1163 \mathrm{~cm}^{-1}$ (C-O-C anti-symmetric bridge stretching), $1033 \mathrm{~cm}^{-1}$ due to $\mathrm{C}-\mathrm{O}-\mathrm{C}$ (ether linkage) of the glycosidic unit, $903 \mathrm{~cm}^{-1}$ ( $\beta$ glycosidic linkages between the sugar units)). The presence of a wide band in the region $3100-3500 \mathrm{~cm}^{-1}$ (stretching vibrations of $\mathrm{OH}$ ) and the presence of a band at $1647 \mathrm{~cm}^{-1}$ (due to $\mathrm{H}-\mathrm{O}-\mathrm{H}$ bending) indicate the presence of water adsorbed on the fibers surface [27, 28]. A variation of the intensity of $\mathrm{OH}$ stretching band can be observed, which can be attributed rather to the water adsorption on the surface of CA fibers than to chemical modification induced by solvents [26]. The different water adsorption degrees could also indicate some modifications on the crystalline structure of the CA fibers induced by solvents (higher crystallinity degree, lower water adsorption) [26].

\section{Morphological characterization}

Figure 2 shows the SEM images of the electrospun CA fibers prepared from binary solvent system DMF/Acetone at different $v / v$ ratios: $1 / 0$ (figure 2, a), $3 / 1$ (figure 2, b), 1/1 (figure 2, c), 1/3 (figure 2, d), 0/1 (figure 2, e). By using DMF as single solvent (figure 2 , a) and by adding acetone in a ratio of $3 / 1 \mathrm{v} / \mathrm{v}$, only beads with micron size were obtained (figure $2, b$ ). By increasing the concentration of acetone to $1 / 1 \mathrm{v} / \mathrm{v}$, very thin fibers with a diameter of about $74 \mathrm{~nm}$ start to appear on big beads with diameters around 2000 m (figure 2,c). By using a binary solvent system of DMF/acetone with a ratio of $1 / 3 \mathrm{v} / \mathrm{v}$, fibers with an average diameter of about $298 \mathrm{~nm}$ with discrete beads were obtained (figure 2, d). By using acetone as single solvent, fibers without beads with an average diameter of $3750 \mathrm{~nm}$ were obtained (figure 2, e). The physical properties of solvents have a major influence on the electrospun products. Because DMF

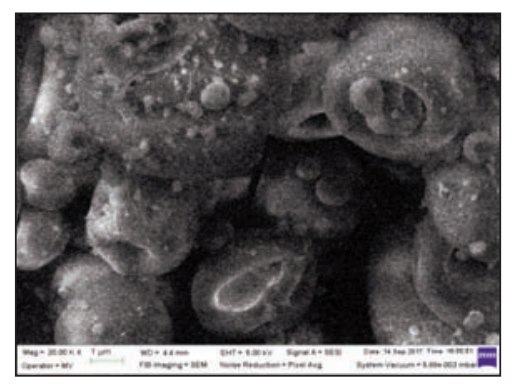

a

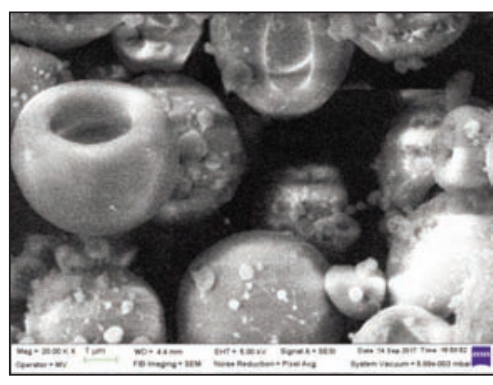

b

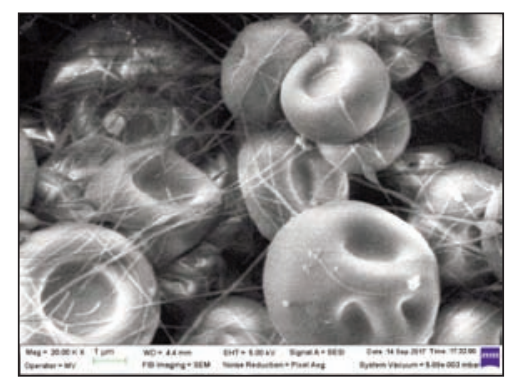

c

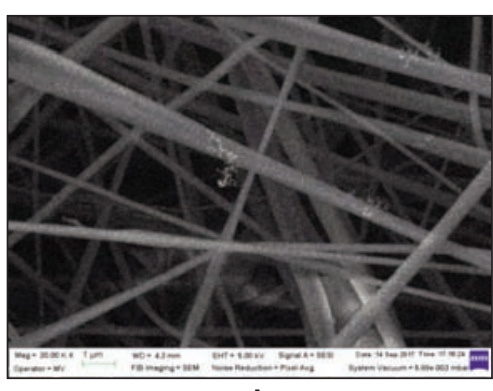

d

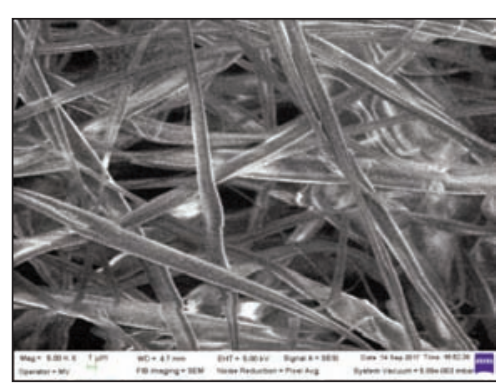

e

Fig. 2. SEM images of electrospun CA fibers obtained from D/A binary solvent system at different $v / v$ ratios: $1 / 0$ (a), 3/1(b), 1/1 (c), 1/3 (d) (20 kx magnification), and 0/1 (e) (5 kx magnification) 


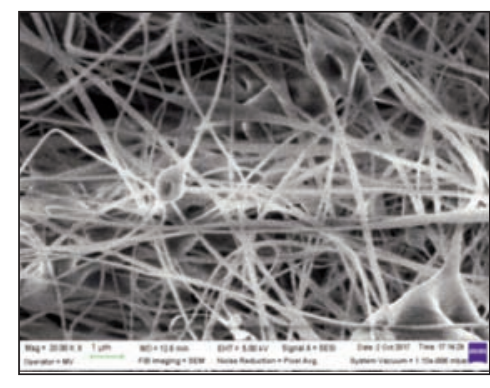

a

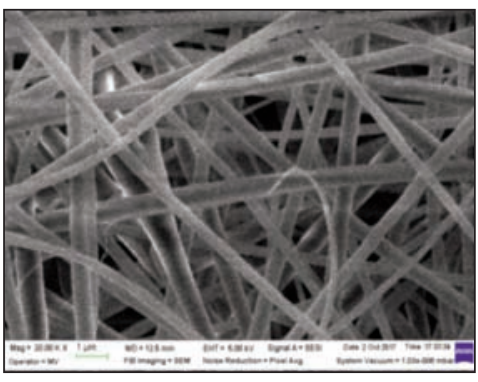

C

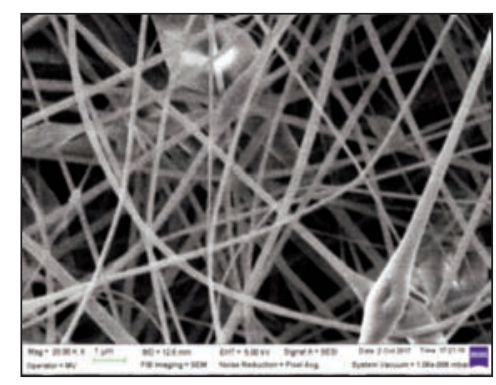

b

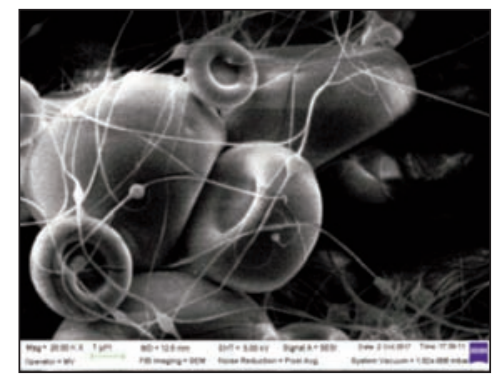

d
Fig. 3. SEM images of electrospun CA fibers obtained from D/A/C ternary solvent system at different $\mathrm{v} / \mathrm{v} / \mathrm{v}$ ratios: 1/1/1 (a), 1/1/2(b), $1 / 2 / 1$ (c), and 2/1/1 (d) (20 kx magnification)

with smooth surface, uniform diameters and beads-free were obtained, but the fibers have higher diameters of about 440 $\mathrm{nm}$. By increasing the amount of DMF (D/A/C ratio $2 / 1 / 1$ - figure $3, d$ ), beads with discrete fibers with average diameters of about $58 \mathrm{~nm}$ were obtained.

\section{Wettability testing of the fibers}

To analyse the wettability of the different nonwoven electrospun CA fibers using D/A solvent system, water contact angles were measured (figure 4). A tendency of the obtained nonwoven CA fibers is the decreasing of the contact angle with the increasing of the amount of acetone in the solvent system. The decrease of the contact angle starts from $130.9^{\circ}$ for the CA fibers prepared with D/A solvent system $1 / 0$ to $126.5^{\circ}$ for the CA fibers prepared with D/A solvent system 1/1, until $124.5^{\circ}$ for the CA fibers prepared with D/A solvent system $0 / 1$. For electrospun CA samples obtained from the D/A solvent system $3 / 1$ and $1 / 0$ it was observed

has a higher boiling point and a higher surface tension, only beads were obtained in comparison to acetone that presents a lower value of these physical parameters. For this reason, when we used acetone as solvent, we obtained fibers. Because of the high boiling point of DMF, during the electrospinning process the ejected charging jet of the solution do not have enough time to dry, and for this reason only droplets were obtained. When using acetone as solvent for obtaining CA fibers, some problems appeared because the needle tip was easily blocked with polymer due to the fast solvent evaporation. By using a binary solvent system of DMF/acetone in a ratio of $1 / 3 \mathrm{v} / \mathrm{v}$ these problems were partially solved, the overall volatility of the solvent system was reduced, and as a consequence fibers with discrete beads were obtained.

Figure 3 illustrates the SEM images for electrospun CA fibers prepared from ternary solvent system DMF/Acetone/Chloroform at different v/v/v ratios: 1/1/1 (figure 3, a), 1/1/2 (figure 3, b), 1/2/1 (figure 3, c) and $2 / 1 / 1$ (figure $3, d$ ). Chloroform physical properties (table 3) exhibit values that are intermediate between DMF and acetone, and by adding this in the ternary solvent system we tried to control the overall properties of the final solution.

By using a mixture of solvents in equal parts (D/A/C solvent system with the volumetric ratio $1 / 1 / 1$ - figure 3 , a), fibers with $198 \mathrm{~nm}$ average diameter and with droplets were obtained. By increasing the amount of chloroform in the solvent system (D/A/C solvent system with the volumetric ratio $1 / 1 / 2$ - figure $3, b$ ), fibers with higher average diameter of about $235 \mathrm{~nm}$ were obtained, and the droplets diameter increased as well. When using a ternary solvent system with a higher concentration of acetone (D/A/C solvent system with the volumetric ratio $1 / 2 / 1$ - figure $3, c)$, fibers that after 20 seconds the contact angle decreased to the value of $55^{\circ}$, respectively $53^{\circ}$. So, the nonwoven fiber mats exhibit an intermediate hydrophilic behaviour. This behaviour appeared most probably due to the morphology of the electrospun CA fibers and the presence of the droplets which results in lower contact angles.

In the case of electrospun nonwoven CA fibers prepared from DMF/Acetone/Chloroform ternary solvent system, the contact angle (table 4) did not present a

Table 4

\begin{tabular}{|c|c|}
\hline Sample & Contact angle (degree) \\
\hline DAC111 & 128.5 \\
\hline DAC112 & 129.4 \\
\hline DAC121 & 131.2 \\
\hline DAC211 & 130.0 \\
\hline
\end{tabular}

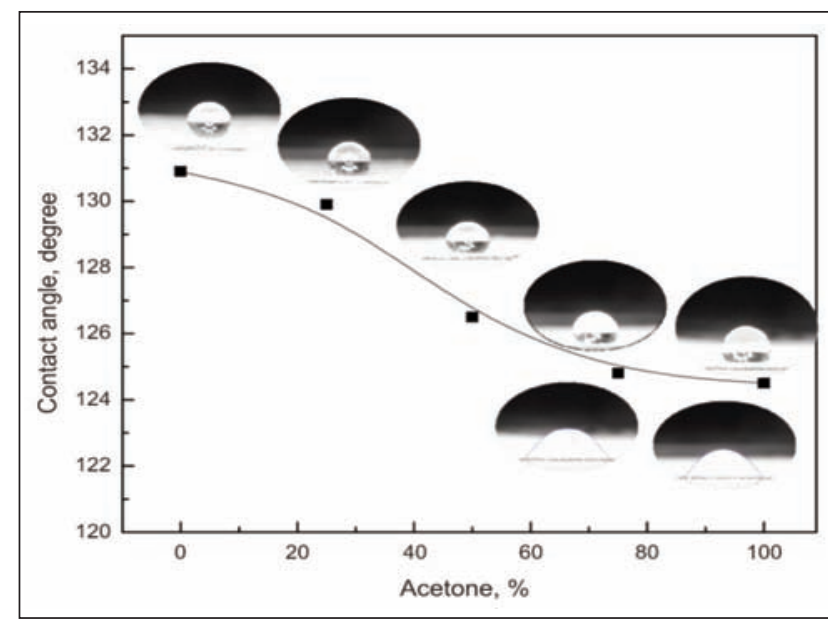

Fig. 4. Contact angle for the electrospun nonwoven CA prepared from DMF/acetone binary solvent system 


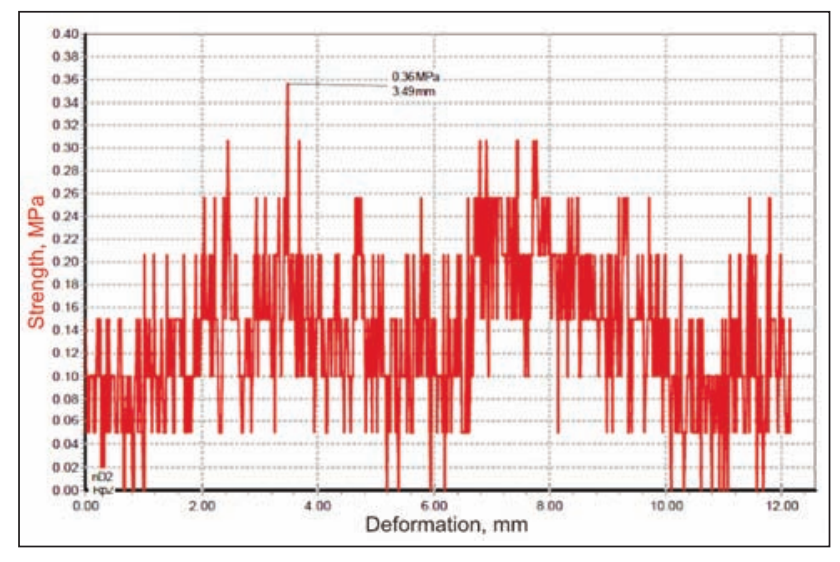

a

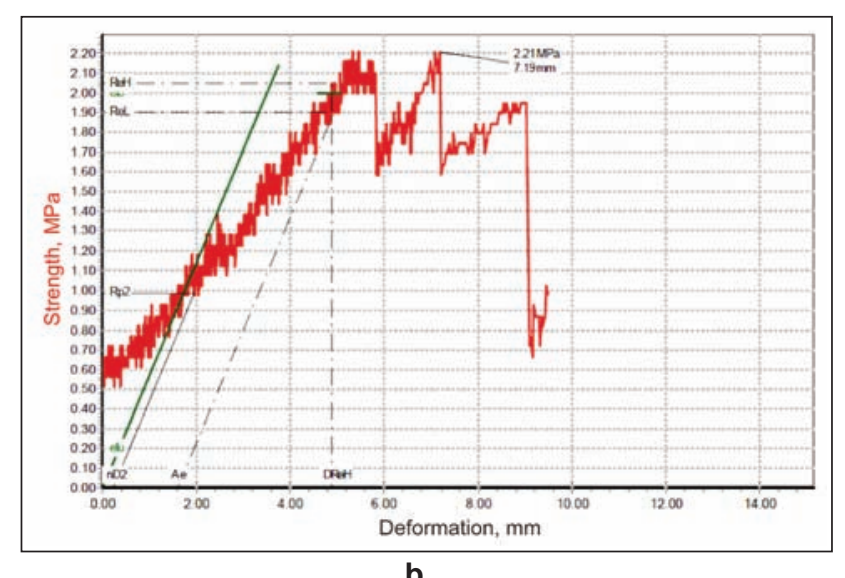

b

Fig. 5. Tensile strength curves of the CA fibers prepared using D/A/C ternary solvent system 1/1/2 (a) and 1/2/1 (b)

considerable variation, which remained constant at about $128^{\circ}-131^{\circ}$. By adding chloroform in the solvent system we noticed a small influence to the hydrophobicity by increasing the contact angle of the sample prepared with the highest amount of acetone.

\section{Mechanical characterisation}

In order to perform the tensile strength measurement, the CA fibers were electrospun for 6 hours on a textile substrate (gauze fabric). Tensile strength was performed only for the samples prepared with ternary solvent system D/A/C 1/1/2 (figure 5, a) and $1 / 2 / 1$ (figure $5, b$ ), because these samples could be prepared and handled for test with minimal damage on the structure of the mats. The rest of the samples prepared using the solvent systems $\mathrm{D} / \mathrm{A} / \mathrm{C}$ ratio $1 / 1 / 1$ and 2/1/1 were quite weak and were damaged very easily when handled.

Tensile strength tests were carried out with a drawing speed of $50 \mathrm{~mm} /$ minute on rectangular samples with the size of $100 \mathrm{~mm} \times 20 \mathrm{~mm}$. For each type of material five tests were carried out and then an average value of the obtained parameters was calculated.

In the case of the samples obtained using the solvent system D/A/C 1/1/2, the tensile strength was 0.44 $\mathrm{MPa}$ and it increased until 2.77 MPa for the samples prepared using the solvent system D/A/C 1/2/1. This increase appears due to the smooth and uniform diameter fibers obtained and the absence of the beads in the mats. The presence of beads in the fibers mats acts as defects and leads to a lower number of fibers and lower interactions between them and therefore lower values of the tensile strength are obtained.

\section{CONCLUSIONS}

In the research which was carried out, the cellulose acetate fibers were obtained by electrospinning using polymer solutions prepared from simple, binary and ternary solvents systems containing the following solvents: N,N-dimethylformamide, acetone and chloroform.

When using the DMF/Acetone binary solvent system, fibers with discrete beads were obtained by electrospinning. When using the ternary solvent system DMF/Acetone/Chloroform for preparing the electrospinning cellulose acetate solution, a uniform morphology of the fibers was obtained, these fiber mats having a tensile strength up to $2.77 \mathrm{MPa}$.

During these experiments, the morphology of electrospun cellulose acetate fibers was controlled by modifying the physical parameters of the solvent systems (binary or ternary), thus continuous, uniform and smooth fibers were obtained by using a cellulose acetate solution prepared with the solvent system DMF/Acetone/Chloroform in a volumetric ratio of 1/2/1.

\section{ACKNOWLEDGMENT}

This work was supported by the project PN 16110205/2016 (CORE Program) and the project 113PED/2017.

\section{BIBLIOGRAPHY}

[1] Konwarh, R., Karak, N., Misra, M. Electrospun cellulose acetate nanofibers: The present status and gamut of biotechnological applications, In: Biotechnology Advances, 2013, vol. 31, no. 4, pp. 421-437.

[2] Ohkawa, K. Nanofibers of cellulose and its derivatives fabricated using direct electrospinning, In: Molecules, 2015, vol. 20, pp. 9139-9154.

[3] Kanagaraj, P., Neelakandan, S., Nagendran, A. Preparation, characterization and performance of cellulose acetate ultra filtration membranes modified by charged surface modifying macromolecule, In: Korean J. Chem. Eng., 2014, vol. 31(6), pp. 1057-1064.

[4] Arslan, O., Aytac, Z., Uyar, T. Superhydrophobic, hybrid, electrospun cellulose acetate nanofibrous mats for oil/water separation by tailored surface modification, In: ACS Appl. Mater. Interfaces, 2016, vol. 8, pp. 19747-19754.

[5] Zhang, X., Chan-Yu-King, R., Jose, A., Manohar, S.K. Nanofibers of polyaniline synthesized by interfacial polymerization, Synthetic Metals, In: 2004, vol. 145(1), pp. 23-29.

[6] Ellison, C.J., Phatak, A., Giles, D.W., Macosko, C.W. Bates, F.S. Melt blown nanofibers: Fiber diameter distributions and onset of fiber breakup, In: Polymer, 2007, vol. 48, pp. 3306-3316. 
[7] Medeiros, E.S., Glenn, G.M., Klamczynski, A.P., Orts, W.J., Mattoso, L.H.C. Solution blow spinning: A new method to produce micro- and nanofibers from polymer solutions, In: Journal of Applied Polymer Science, 2009, vol. 113(4), pp. 2322-2330.

[8] Chitanu, E., Bara, A., Patroi, D., Marinescu, V., Codescu, M.M., Banciu, C. PAN/ZnO composite electrospun fibers for UV shielding applications, In: $10^{\text {th }}$ International Symposium on Advanced Topics in Electrical Engineering (ATEE), March 23-25, 2017, Bucharest, Romania, IEEE, pp. 227-230, DOI: 10.1109/ATEE.2017.7905098

[9] Banciu, C., Bara, A., Chitanu, E., Lungulescu, M., Ion, I., Leonat, L. Filtering membranes based on electrospun expanded polystyrene/ $\beta$-cyclodextrin fibers, In: $10^{\text {th }}$ International Symposium on Advanced Topics in Electrical Engineering (ATEE), March 23-25, 2017, Bucharest, Romania, IEEE, pp. 223-226, DOI: 10.1109/ATEE.2017.7905084

[10] Liu, H., Tang, C. Electrospinning of Cellulose Acetate in Solvent Mixture N,N-Dimethylacetamide (DMAc)/Acetone, In: Polymer Journal, 2007, vol. 39(1), pp. 65-72.

[11] Bara, A., Marinescu, V., Chitanu, E., Banciu, C., Clicinschi, F. Influence of process parameters on the morphology of polyacrylonitrile electrospun fibers, In: Industria Textila, 2015, vol. 66(4), pp. 232-239.

[12] Liu, X., Lin, T., Gao, Y. Antimicrobial electrospun nanofibers of cellulose acetate and polyester urethane composite for wound dressing, In: J. Biomed. Mater. Res. Part B, 2012, vol. 100B(6), pp. 1556-1565.

[13] Gouda, M., Hebeish, A.A., Aljafari, Al. Synthesis and characterization of novel drug delivery system based on cellulose acetate electrospun nanofiber mats, In: Journal of Industrial Textiles, 2014, vol. 43(3), pp. 319-329.

[14] Farack, J., Wolf-Brandstetter, C., Glorius, S., Nies, B., Standke, G., Quadbeck, P., Worch, H., Scharnweber, D. The effect of perfusion culture on proliferation and differentiation of human mesenchymal stem cells on biocorrodible bone replacement material, In: Materials Science and Engineering B, 2011, vol. 176, pp. 1767-1772.

[15] Rodríguez, K., Gatenholm, P., Renneckar, S. Electrospinning cellulosic nanofibers for biomedical applications: Structure and in vitro biocompatibility, In: Cellulose, 2012, vol. 19, pp. 1583-1598.

[16] Sun, T., Hayat Khan, T., Sultana, N. Fabrication and in vitro evaluation of nanosized hydroxyapatite/chitosan-based tissue engineering scaffolds, In: Journal of Nanomaterials, 2014, vol. 2014, Article ID 194680, 8 pages, http://dx.doi.org/10.1155/2014/194680

[17] Tungprapa, S., Puangparn, T., Weerasombut, M., Jangchud, I., Fakum, P., Semongkhol, S., Meechaisue, C., Supaphol, P. Electrospun cellulose acetate fibers: effect of solvent system on morphology and fiber diameter, In: Cellulose, 2007, vol.14, pp. 563-575, DOI 10.1007/s10570-007-9113-4

[18] Ghorani, B., Russell, S.J., Goswami, P. Controlled morphology and mechanical characterisation of electrospun cellulose acetate fibre webs, In: International Journal of Polymer Science, 2013, vol. 2013, Article ID 256161, 12 pages.

[19] Wook Kim, S., Ok Han, S., Sim, I.N., Young Cheon, J., Ho Park, W. Fabrication and characterization of cellulose acetate/montmorillonite composite nanofibers by electrospinning, In: Journal of Nanomaterials, 2015, vol. 2015, Article ID 275230, 8 pages.

[20] Liu, H., Tang, C. Electrospinning of cellulose acetate in solvent mixture N,N-dimethylacetamide (DMAc)/acetone, In: Polymer Journal, 2007, vol. 39, pp. 65-72.

[21] Wei, N., Sun, C., Wang, J., Qiang Huang, L. Research on electrospinning of cellulose acetate prepared by acetone/DMAc solvent, In: Applied Mechanics and Materials, 2014, vol. 469, pp. 126-129.

[22] Cai, J., Niu, H., Yu, Y., Xiong, H., Lin, T. Effect of solvent treatment on morphology, crystallinity and tensile properties of cellulose acetate nanofiber mats, In: The Journal of The Textile Institute, 2017, vol. 108(4), pp. 555-561.

[23] Ok Han, S., Ho Youk, J., Dan Min, K., Ho Park, W. Electrospinning of cellulose acetate nanofibers using a mixed solvent of acetic acid/water: Effects of solvent composition on the fiber diameter, In: Materials Letters, 2008, vol. 62(4-5), pp. 759-762.

[24] Luo, C., Stride, E., Edirisinghe, M. Mapping the influence of solubility and dielectric constant on electrospinning polycaprolactone solutions, In: Macromolecules, 2012, vol. 45(11), pp. 4669-4680.

[25] Kamal, H., Abd-Elrahim, F.M., Lotfy, S. Characterization and some properties of cellulose acetate-co-polyethylene oxide blends prepared by the use of gamma irradiation, In: J. Radiat. Res. Appl. Sci., 2014, vol. 7, pp. 146-15.

[26] Valente, A.J.M., Polishchuck, A.Y., Burrows, H.D., Lobo, V.M.M., Permeation of water as a tool for characterizing the effect of solvent, film thickness and water solubility in cellulose acetate membranes, In: Eur. Polym. J., 2005, vol. 41, pp. 275-281.

[27] Zavastin, D., Cretescu, I., Bezdadea, M., Bourceanu, M., Dragan, M., Lisa, G., Mangalagiu, I., Vasic, V., Savic, J., Preparation, characterisation and applicability of cellulose acetate-polyurethane blend membrane in separation techniques, In: Colloids and Surfaces A: Physicochem. Eng. Aspects, 2010, vol. 370, pp. 120-128.

[28] Pielesz, A., Binias, W. Cellulose acetate membrane electrophoresis and FTIR spectroscopy as methods of identifying a fucoidan in Fucus vesiculosus Linnaeus, In: Carbohydrate Research, 2010, vol. 345(18), pp. $2676-2682$.

\section{Authors:}

ELENA CHIȚANU, ADELA BĂRA, CRISTINA BANCIU, MARIUS LUNGULESCU, VIRGIL MARINESCU

National Institute for Research and Development in Electrical Engineering ICPE-CA,

313 Spl. Unirii, 030138, Bucharest, Romania

e-mail: elena.chitanu@icpe-ca.ro; adela.bara@icpe-ca.ro; cristina.banciu@icpe-ca.ro; marius.lungulescu@icpe-ca.ro; virgil.marinescu@icpe-ca.ro

Corresponding authors:

ADELA BĂRA, CRISTINA BANCIU

e-mail: adela.bara@icpe-ca.ro; cristina.banciu@icpe-ca.ro 